\title{
Jugular venous desaturation and outcome after head injury
}

\author{
S P Gopinath, C S Robertson, C F Contant, C Hayes, Z Feldman, R K Narayan, \\ R G Grossman
}

\begin{abstract}
Early experience with continuous monitoring of jugular venous oxygen saturation $\left(\mathrm{SjvO}_{2}\right)$ suggested that this technology might allow early identification of global cerebral ischaemia in patients with severe head injury. The purpose of the present study was to examine the relationship between episodes of jugular venous desaturation and neurological outcome. One hundred and sixteen severely head-injured patients had continuous monitoring of $\mathrm{SjvO}_{2}$ during days 1-5 after injury. Episodes of jugular venous desaturation (SjvO $2<50 \%$ for more than 10 minutes) were prospectively identified, and the incidence of desaturation was correlated with neurological outcome: 77 episodes of desaturation occurred in 46 of the 116 patients; 27 had one episode and 19 had multiple episodes of desaturation. The causes of these episodes were systemic $(n=36)$, cerebral $(n=35)$, or both $(n=6)$. Most of the episodes were less than 1 hour in duration, and it is probable that many of them would not have been detected without continuous measurement of $\mathrm{SjvO}_{2}$. Episodes of desaturation were most common on day 1 after injury, and were twice as common in patients with a reduced cerebral blood flow as in patients with a normal or elevated cerebral blood flow. The occurrence of jugular venous desaturation was strongly associated with a poor neurological outcome. The percentage of patients with a poor neurological outcome was $90 \%$ with multiple episodes of desaturation and $74 \%$ in patients with one desaturation, compared to $55 \%$ in patients with no episodes of desaturation. When adjusted for all co-variates that were found to be significant, including age, Glasgow coma score, pupillary reactivity, type of injury, lowest recorded cerebral perfusion pressure, and highest recorded temperature, the incidence of desaturation remained significantly associated with a poor outcome. Although a cause and effect relationship with outcome cannot be established in this study, the data suggest that monitoring $\mathrm{SjvO}_{2}$ might allow early identification and therefore treatment of many types of secondary injury to the brain.
\end{abstract}

$(\mathcal{F}$ Neurol Neurosurg Psychiatry 1994;57:717-723)
A number of physiological factors have been related to outcome after severe head injury. Intracranial hypertension, systemic hypotension, arterial hypoxia, and hypocapnia have been implicated as causes of cerebral hypoxia/ischaemia and have been associated with a poor neurological outcome. ${ }^{1-6}$

Early experience with continuous monitoring of jugular venous oxygen saturation $\left(\mathrm{SjvO}_{2}\right)$ using a fibroptic catheter had suggested that this technology might allow early identification of both cerebral ischaemia resulting from systemic and cerebral causes and transient episodes of ischaemia which would otherwise go undetected and untreated. ${ }^{7-12}$ More recent studies have suggested that $\mathrm{SjvO}_{2}$ monitoring might help determine optimal hyperventilation ${ }^{13}$ and, combined with transcranial Doppler measurements, optimal cerebral perfusion pressure. ${ }^{14} 15$ The purpose of the present study was to examine the relationship between episodes of jugular venous desaturation and neurological outcome in patients who had sustained a severe head injury.

\section{Patients and methods}

PATIENT POPULATION AND MANAGEMENT

Between 15 July 1989 and 30 September 1992, 116 patients admitted consecutively to Ben Taub General Hospital, Houston, Texas, USA, with a severe head injury (Glasgow coma scale, GCS $\leqslant 8$ ) had continuous measurements of $\mathrm{SjvO}_{2}$ using a fibroptic oxygen saturation catheter (4 French gauge catheter, Abbott Laboratories, North Chicago IL, United States) positioned in the jugular bulb. The accuracy of the oxygen saturation measurements obtained with this catheter has been described in a previous publication. ${ }^{12}$ The protocol was approved by the Baylor Institutional Review Board and informed consent was obtained from the families of the patients participating in the study.

Ninety per cent of the patients studied were male; most were between the ages of 16 and 35 , with an average age of 31.5 (SD 14.7) years. Eighty-six per cent of the patients studied had a closed head injury, whereas the remaining $14 \%$ had a gunshot wound to the head. Eighty per cent of the patients were comatose on admission to the hospital. The GCS after resuscitation was $3-5$ in $34 \%$ of the patients and $6-8$ in $46 \%$. Twenty per cent of the patients had an initial GCS of $>8$, but deteriorated to coma within 48 hours of injury. The average GCS was 6.9 (SD 3.0) on 
arrival in the emergency room, and 6.8 (SD $2 \cdot 3$ ) on day 1 after injury.

All patients were managed with a protocol that emphasised prompt evacuation of intracranial haematomas and prevention of secondary insults to the brain. Patients were intubated and ventilated to maintain a $\mathrm{PaO}_{2}$ of at least $100 \mathrm{mmHg}$ and a $\mathrm{PaCO}_{2}$ of about $35 \mathrm{mmHg}$. Intracranial pressure (ICP) was monitored, usually by ventriculostomy, and pressure $>20 \mathrm{mmHg}$ were treated. Intracranial hypertension was treated with cerebrospinal fluid drainage, hyperventilation ( $\mathrm{PaCO}_{2}$ 25-30 mmHg), sedation, paralysis, and mannitol. Mean arterial blood pressure (MAP) was continuously monitored and maintained so that cerebral perfusion pressure (CPP) was at least $60 \mathrm{mmHg}$. Barbiturate coma was used only if intracranial hypertension was refractory to the above regimen. Other routine medications included phenytoin and antibiotic drugs.

CONTINUOUS PHYSIOLOGICAL MEASUREMENTS

To monitor $\mathrm{SjvO}_{2}$, the fibroptic catheter was inserted into the internal jugular vein through a 4.5 French gauge peel-away introducer (Cook Critical Care, Bloomington Ind., United States), and threaded into the jugular bulb. The catheter for measurement of $\mathrm{SjvO}_{2}$ was placed on the right side unless the left jugular venous circulation was demonstrated to be dominant: $96(83 \%)$ were placed on the right side and $20(17 \%)$ on the left. A radiograph was obtained to ensure that the catheter was correctly positioned in the jugular bulb. Every effort was made to start the monitoring as early after admission as possible. The catheter for measurement of $\mathrm{SjvO}_{2}$ was inserted an average of 16.6 (SD 15.0) hours after admission to the neuro-intensive care unit: 93 $(80 \%)$ were inserted within 24 hours of admission. Where monitoring was started more than 24 hours later, reasons included: inability to obtain informed consent from families $(n=6)$, early contraindication for jugular catheter such as coagulopathy or suspicion of a cervical spine injury $(n=3)$, and neurological deterioration after 24 hours $(n=14)$. Patients were monitored for an average of $88 \cdot 2$ (SD $75 \cdot 5)$ hours.

The following physiological parameters were recorded at an interval of 1-2 minutes, stored in a computerized database, plotted against time, and correlated with clinical events and intermittent measurements of cerebral blood flow (CBF) and cerebral metabolism: ICP, mean arterial blood pressure (MAP) via a radial artery cannula, CPP, arterial oxygen saturation $\left(\mathrm{SaO}_{2}\right)$, endtidal $\mathrm{CO}_{2}$, and $\mathrm{SjvO}_{2}$. The catheter for measurement of $\mathrm{SjvO}_{2}$ was calibrated before insertion using the standard provided by the manufacturer. In addition, an in vivo calibration was performed after insertion, and every eight hours thereafter, if the difference between the catheter value and the $\mathrm{SO}_{2}$ measured in a blood sample drawn through the catheter was more than $4 \%$.
IDENTIFICATION AND MANAGEMENT OF JUGULAR VENOUS DESATURATION

Episodes of jugular venous desaturation, defined as an $\mathrm{SjvO}_{2}<50 \%$ for more than 10 minutes, were identified prospectively. The first task was to verify the accuracy of the catheter at the time of the desaturation, this is because, as discussed in a previous report, the catheter is subject to artefactual readings from movement of the catheter within the jugular bulb. ${ }^{12}$ In the 116 patients, 172 episodes of jugular venous desaturation were identified initially. On investigation, $95(55 \cdot 2 \%)$ of the episodes could not be confirmed by measuring $\mathrm{SO}_{2}$ in a blood sample drawn through the catheter.

Once it was confirmed that the $\mathrm{SjvO}_{2}$ was $<50 \%$ in a blood sample drawn through the catheter, it was necessary to identify the cause. Systemic causes of reduced oxygen delivery were sought by examining blood pressure, arterial blood gases, and haemoglobin concentration; ICP and CPP were noted. If an obvious cause was not found, cerebral blood flow was measured. When a remediable cause for the desaturation was found the appropriate treatment was applied.

\section{INTERMITTENT MEASUREMENTS OF CBF AND METABOLISM}

CBF was measured by the nitrous oxide saturation method every eight hours. ${ }^{16}$ A total of 1042 measurements of CBF or an average of nine measurements per patient (range 1-29 per patient) were obtained. Arterial and jugular venous blood samples were obtained together with measurements of CBF for determination of $\mathrm{PaO}_{2}, \mathrm{PaCO}_{2} \mathrm{pH}$, oxygen saturation, lactate, and haemoglobin concentration. A blood gas analyser was used to measure $\mathrm{PaO}_{2}$, $\mathrm{PaCO}_{2}$, and $\mathrm{pH}$. Oxygen saturation and haemoglobin concentration were measured on a co-oximeter (IL-282, Instrumentation Laboratories, Lexington Mass., United States). Patients were classified as having a normal, elevated, or reduced $\mathrm{CBF}$, through comparison of the individual measurements with the normal range for CBF at the patient's $\mathrm{PaCO}_{2}$, as described in a previous publication. ${ }^{16}$

DETERMINATION OF NEUROLOGICAL OUTCOME Outcome was determined three months after injury by personnel who were unaware of the desaturation information. The Glasgow outcome scale (GOS) was used to quantify the severity of the neurological deficits. For comparison of the outcome with the $\mathrm{SjvO}_{2}$ data, a favourable outcome was defined as a GOS score of good recovery or moderate disability, and a poor outcome was defined as a GOS score of severe disability, vegetative, or dead.

\section{STATISTICAL METHODS}

Summary data are reported as the mean \pm standard deviation. Categorical variables were analysed using $\chi$-square whereas differences in means were tested using a one-way analysis 
of variance. Statistical significance was defined as $\mathrm{p}<0.05$ for primary effects.

Multiple logistic regression analysis was used to determine the contribution of more than one variable to the outcome and to the occurrence of desaturations. The model was fitted in a forward selection manner. Covariates in the multiple logistic regressions were included when $p<0 \cdot 20$. The final model contains only those additional variables that were significantly associated with outcome.

\section{Results}

CONFIRMED EPISODES OF JUGULAR VENOUS DESATURATION

Seventy-seven episodes of jugular venous desaturation, defined as $\mathrm{SjvO}_{2}<50 \%$ for more than 10 minutes, were identified prospectively and confirmed in 46 of 116 patients. The episodes were confirmed by measuring $\mathrm{SO}_{2}$ in a blood sample drawn through the catheter.
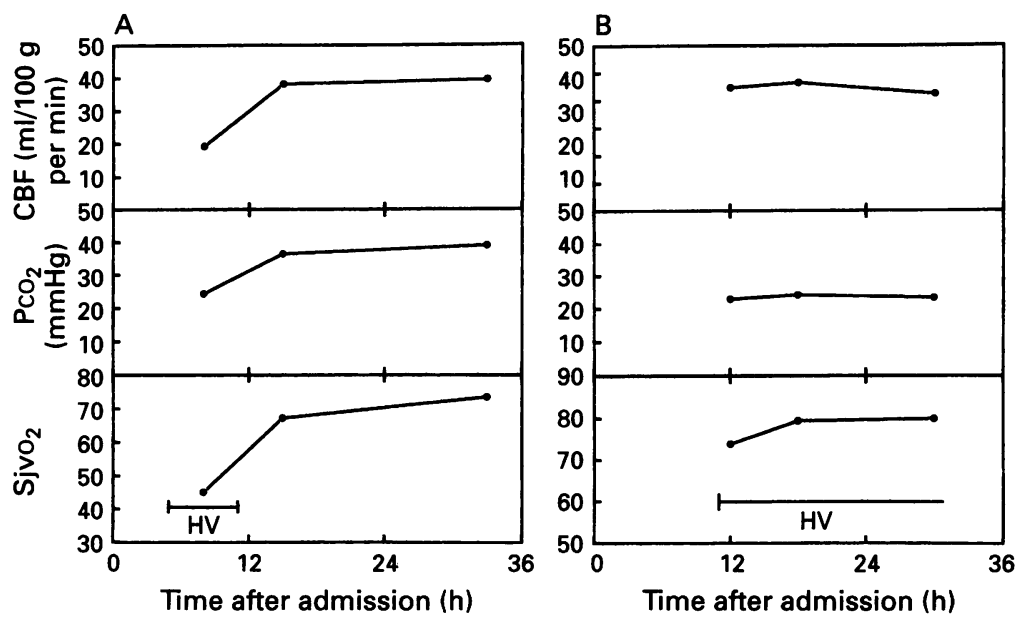

Figure 1 Two patients exhibiting different effects of hyperventilation on $\mathrm{SjvO}_{2}$. The patient whose data are shown in $A$ had a marked decrease in $\mathrm{CBF}$ and $\mathrm{SjvO}_{2}$ when $\left(\mathrm{PCO}_{2}\right.$ was decreased to $3.3 \mathrm{kPa}(25 \mathrm{mmHg})$. These abnormalities reversed when the ventilator was adjusted to normalise $P C O_{2}$. The patient whose data is shown in $B$ had acceptable $\mathrm{CBF}$ and $\mathrm{SjvO}_{2}$ with similar $\mathrm{PCO}_{2}$ values of $2 \cdot 7-3 \cdot 3 \mathrm{kPa}(20-25 \mathrm{mmHg})$.
The $\mathrm{SjvO}_{2}$ values at the time of the identification ranged from $17 \%$ to $49 \%$, averaging $39 \cdot 3 \pm 11 \cdot 7 \%$.

Twenty-seven $(23.3 \%)$ of the patients had one episode, $11(9.5 \%)$ two episodes, and eight $(6.9 \%)$ more than two episodes of desaturation. Demographic characteristics, type of injury, severity of injury, and presence of systemic injuries were not significantly related to the incidence of desaturation (table 1).

The incidence of jugular venous desaturation was more common early after injury. Twenty-eight $(36 \cdot 8 \%)$ of the 77 episodes of desaturation occurred within 24 hours of admission to the neuro-intensive care unit. There were 13, 10,12, and seven episodes on days 2-5 after injury, respectively. Only seven episodes occurred after day 5 , with a mean onset of the episodes of desaturation of 53.9 (SD 47.9) hours after admission to the nonintensive care unit.

Duration of the 77 episodes of desaturation ranged from 15 minutes to five hours; 57 $(75 \%)$ were less than one hour. The mean duration of all the episodes was $1 \cdot 2$ (SD 1.6) hours.

The causes of the jugular venous oxygen desaturation could be identified as having a cerebral origin in 35 episodes, arising from intracranial hypertension in 34 and vasospasm in one case. The most common systemic cause was hypocarbia, defined as a $\mathrm{PaCO}_{2}<$ $3.7 \mathrm{kPa}(28 \mathrm{mmHg})(n=21)$, followed by systemic hypotension, defined as systolic blood pressure $<90 \mathrm{mmHg}(n=8)$, arterial hypoxia, defined as an $\mathrm{SaO}_{2}<90 \%(n=6)$, and anaemia $(n=1)$. Combinations of both systemic and cerebral causes were observed in six episodes.

\section{UNIQUE INFORMATION PROVIDED BY}

MONITORING OF $\mathrm{SjvO}_{2}$

An example of hypocarbia producing jugular venous desaturation is given in figure 1 which illustrates two patients with very different responses to lowering $\mathrm{PCO}_{2}$ to $3.3 \mathrm{kPa}$ (25 $\mathrm{mmHg}$ ). One patient developed a very low $\mathrm{SjvO}_{2}$ and a low CBF which returned to

Table 1 Demographic and injury related parameters which were examined for an effect on the relationship between desaturations and outcome

\begin{tabular}{|c|c|c|c|c|c|c|c|c|}
\hline & \multicolumn{4}{|c|}{ Number of desaturations } & \multicolumn{4}{|c|}{ Three month Glasgow outcome score } \\
\hline & None & One & Multiple & $p$ value ${ }^{\star}$ & $G R / M D$ & $S D / V$ & Dead & $p$ value ${ }^{\star}$ \\
\hline $\begin{array}{l}\text { Number } \\
\text { Age (years) } \\
\text { Sex (\% male) }\end{array}$ & $\begin{array}{l}70 \\
31 \cdot 3(14 \cdot 9) \\
65(92 \cdot 9)\end{array}$ & $\begin{array}{l}27 \\
28 \cdot 5(11 \cdot 6) \\
23(85 \cdot 2)\end{array}$ & $\begin{array}{l}19 \\
36 \cdot 2(16 \cdot 9) \\
16(84 \cdot 2)\end{array}$ & $\begin{array}{l}0 \cdot 23 \\
0 \cdot 37\end{array}$ & $\begin{array}{l}40 \\
28 \cdot 8(13 \cdot 3) \\
37(92 \cdot 5)\end{array}$ & $\begin{array}{l}40 \\
31 \cdot 2(14 \cdot 0) \\
35(87 \cdot 5)\end{array}$ & $\begin{array}{l}36 \\
35 \cdot 0(16 \cdot 5) \\
32(88 \cdot 9)\end{array}$ & $\begin{array}{l}0.18 \\
0.75\end{array}$ \\
\hline $\begin{array}{l}\text { Severity of injury } \\
\text { ER GCS (score) } \\
\text { ER pupils (\% normal) } \\
\text { Day } 1 \text { GCS (score) } \\
\text { Day } 1 \text { pupils (\% normal) }\end{array}$ & $\begin{array}{c}7 \cdot 2(3 \cdot 0) \\
53(75 \cdot 7) \\
7 \cdot 0(2 \cdot 1) \\
56(81 \cdot 2)\end{array}$ & $\begin{array}{c}6 \cdot 3(2 \cdot 5) \\
16(59 \cdot 3) \\
6 \cdot 6(2 \cdot 2) \\
24(88 \cdot 9)\end{array}$ & $\begin{array}{c}7 \cdot 0(3 \cdot 5) \\
14(73 \cdot 7) \\
6 \cdot 4(3 \cdot 2) \\
15(78 \cdot 9)\end{array}$ & $\begin{array}{l}0.45 \\
0 \cdot 25 \\
0.61 \\
0.62\end{array}$ & $\begin{array}{c}7 \cdot 6(3 \cdot 1) \\
34(85 \cdot 0) \\
8 \cdot 1(2 \cdot 3) \\
39(97 \cdot 5)\end{array}$ & $\begin{array}{c}6 \cdot 5(2 \cdot 7) \\
29(72 \cdot 5) \\
6 \cdot 7(1 \cdot 8) \\
31(79 \cdot 5)\end{array}$ & $\begin{array}{c}6 \cdot 6(3 \cdot 2) \\
20(55 \cdot 6) \\
5 \cdot 5(2 \cdot 2) \\
25(69 \cdot 4)\end{array}$ & $\begin{array}{c}0.21 \\
0.004 \\
<0.001 \\
<0.001\end{array}$ \\
\hline $\begin{array}{l}\text { Injury type (\%) } \\
\text { Closed head injury } \\
\text { Diffuse } \\
\text { Hematoma } \\
\text { Gunshot wounds }\end{array}$ & $\begin{array}{l}23(60 \cdot 5) \\
36(58 \cdot 1) \\
11(68 \cdot 8)\end{array}$ & $\begin{array}{r}10(26 \cdot 3) \\
14(22 \cdot 6) \\
3(18 \cdot 8)\end{array}$ & $\begin{array}{c}5(13 \cdot 20) \\
12(19 \cdot 4) \\
2(12 \cdot 5)\end{array}$ & $0 \cdot 87$ & $\begin{array}{r}21(55 \cdot 3) \\
16(25 \cdot 8) \\
3(18 \cdot 8)\end{array}$ & $\begin{array}{l}11(28 \cdot 9) \\
19(30 \cdot 6) \\
10(62 \cdot 6)\end{array}$ & $\begin{array}{c}6(15 \cdot 8) \\
27(43 \cdot 5) \\
3(18 \cdot 8)\end{array}$ & 0.001 \\
\hline $\begin{array}{l}\text { Presence of systemic injuries } \\
\text { ISS (score) }\end{array}$ & $26(6)$ & $26(4)$ & $27(5)$ & $0 \cdot 88$ & $26(7)$ & $26(5)$ & $27(4)$ & 0.95 \\
\hline
\end{tabular}
${ }^{\star} \mathrm{p}$ value is for analysis of variance when mean values were compared and the $\chi$ squared test used with categorical data. Values in parentheses are standard
deviations. deviations.

$\mathrm{ER}=$ emergency room (post resuscitation); GCS = Glasgow coma score; ISS = injury severity score; GR = good recovery; $M D=$ moderate disability; $\mathrm{SD}=$ severe disability; $\mathrm{V}=$ vegetative . 


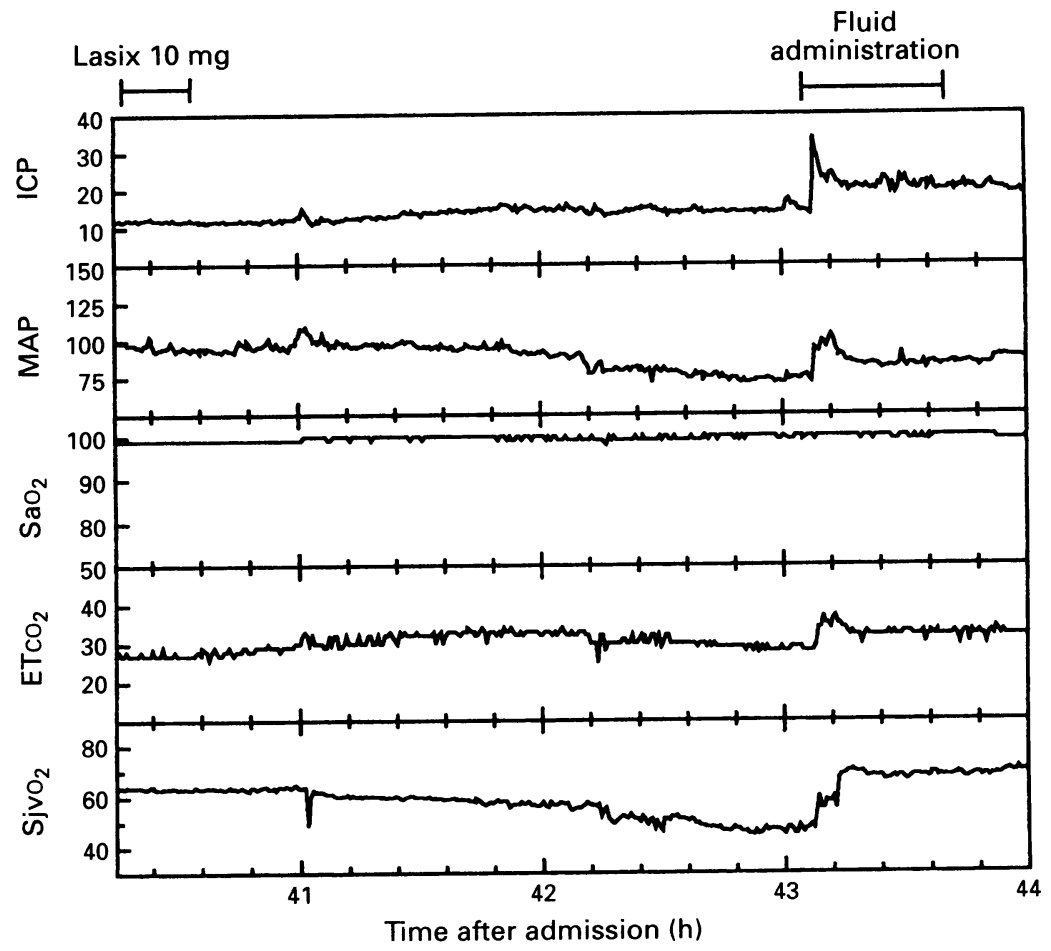

Figure $2 \mathrm{Sjv}_{2}$ recording from a patient who developed jugular venous desaturation as a result of systemic hypotension after a small dose of frusemide (furosemide) had been given. As the blood pressure gradually decreased from 100 to $75 \mathrm{~mm} \mathrm{Hg}$, the $\mathrm{SjvO}_{2}$ also decreased. Both the MAP and the $\mathrm{SjvO}_{2}$ normalised when intravenous fluid was given. $\mathrm{ETCO}_{2}=$ end tidal $\mathrm{CO}_{2}$.
$75 \mathrm{mmHg}$ after a dose of frusemide (furosemide) was given. Although the CPP remained $>60 \mathrm{mmHg}$, the $\mathrm{SjvO}_{2}$ dropped to below $50 \%$. The MAP and $\mathrm{SjvO}_{2}$ values normalised with fluid administration.

\section{RELATIONSHIP OF JUGULAR VENOUS}

DESATURATION AND CEREBRAL BLOOD FLOW

Twenty $(17 \%)$ of the patients had a reduced CBF, averaging $0.352(\mathrm{SD} 0.083) \mathrm{ml} / \mathrm{g}$ per minute; $65(56 \%)$ had an elevated and 31 $(27 \%)$ a normal CBF, averaging 0.606 (SD $0 \cdot 124) \mathrm{ml} / \mathrm{g}$ per minute and 0.422 (SD 0.90 ) $\mathrm{ml} / \mathrm{g}$ per minute, respectively. As shown in figure 3, patients with a reduced CBF were twice as likely to have episodes of jugular venous desaturation as patients with a normal or elevated CBF. Fourteen (70\%) of the 20 patients in the reduced CBF group had either single or multiple episodes of desaturation, compared with nine $(29 \%)$ in the normal CBF group, and $22(34 \%)$ in the elevated $\mathrm{CBF}$ group.

\section{RELATIONSHIP OF JUGULAR VENOUS}

DESATURATION AND NEUROLOGICAL OUTCOME Forty $(34.5 \%)$ of the patients had a favourable outcome three months after injury $(20=$ good recovery, $20=$ moderate disability); $40(34.5 \%)$ survived with a severe disability $(n=26)$ or were vegetative $(n=14)$, and $36(31 \%)$ died. The incidence of jugular venous desaturation was strongly associated with neurological outcome (fig 4). The mortality rate of patients with no episodes of desaturation was $17 \%$, compared to $41 \%$ in patients with one desaturation, and $68 \%$ in those with multiple desaturations. The percentage of patients with a poor neurological outcome (GOS of severe disability, vegetative, or dead) was $55 \%$ in patients with no desaturation, $74 \%$ in those with one desaturation, and $89.5 \%$ in those with multiple desaturations.

The total duration of time that $\mathrm{SjvO}_{2}$ was less than $50 \%$ was significantly longer $(p=0.002)$ in the patients who died than in the patients who survived. The total duration of all the episodes of desaturation averaged

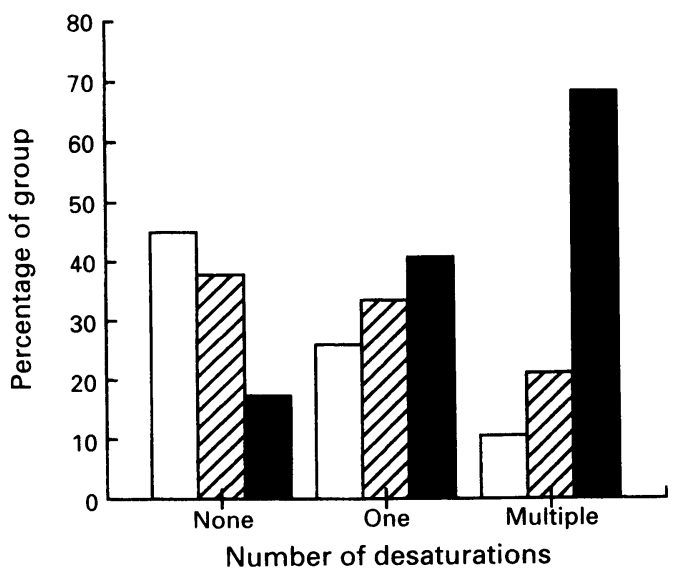

Figure 4 Occurrence of jugular venous desaturation was strongly associated with a high mortality rate and a poor outcome; 3 month Glasgow outcome scale: $\square$ good recovery/ moderate disability; severe disability/vegetative; $\mathbf{\square}$ dead. 
Table 2 Systemic physiological variables that were examined for an effect on the relationship between desaturations and outcome

\begin{tabular}{|c|c|c|c|c|c|c|c|c|}
\hline & \multicolumn{4}{|c|}{ Number of desaturations } & \multicolumn{4}{|c|}{ Three month Glasgow outcome score } \\
\hline & None & One & Multiple & $p$ value ${ }^{\star}$ & $G R / M D$ & $S D / V$ & Dead & $p$ value \\
\hline $\begin{array}{l}\text { Number of patients } \\
\text { BP (mmHg) }\end{array}$ & 70 & 27 & 19 & & 40 & 40 & 36 & \\
\hline Mean & $\begin{array}{l}93(7) \\
68(9)\end{array}$ & $\begin{array}{l}91(10) \\
63(14)\end{array}$ & $\begin{array}{l}85(11) \\
60(13)\end{array}$ & $\begin{array}{l}0.005 \\
0.010\end{array}$ & $\begin{array}{l}94(7) \\
70(8)\end{array}$ & $\begin{array}{l}94(7) \\
69(10)\end{array}$ & $\begin{array}{l}85(11) \\
57(12)\end{array}$ & $\begin{array}{l}<0.001 \\
<0.001\end{array}$ \\
\hline $\begin{array}{l}\mathrm{PaO}_{2} \\
\underset{(\text { mean })}{\mathrm{PaCO}_{2}}(\mathrm{mmHg})\end{array}$ & $173(39)$ & $184(46)$ & $160(39)$ & $0 \cdot 138$ & $174(44)$ & $170(36)$ & $177(45)$ & 0.748 \\
\hline $\begin{array}{l}\text { (mean) (mmHg) } \\
\text { Haemoglobin }\end{array}$ & $32(4)$ & $30(3)$ & $31(3)$ & 0.046 & $32(4)$ & $32(4)$ & $29(2)$ & 0.001 \\
\hline $\begin{array}{l}\text { (mean) (g/dl) } \\
\text { Temperature }\end{array}$ & $10 \cdot 8(2 \cdot 1)$ & $10 \cdot 1(1 \cdot 8)$ & $10 \cdot 6(1 \cdot 8)$ & $0 \cdot 390$ & $10 \cdot 6(2 \cdot 0)$ & $10 \cdot 7(2 \cdot 0)$ & $10 \cdot 4(1 \cdot 9)$ & 0.802 \\
\hline $\begin{array}{l}\text { Mean }\left({ }^{\circ} \mathrm{C}\right) \\
\text { Highest }\end{array}$ & $\begin{array}{l}100 \cdot 5(6) \\
103 \cdot 0(0 \cdot 1)\end{array}$ & $\begin{array}{l}100.2(0.7) \\
102.9(0.2)\end{array}$ & $\begin{array}{l}100 \cdot 1(1 \cdot 0) \\
102 \cdot 7(0 \cdot 3)\end{array}$ & $\begin{array}{l}0.068 \\
0.613\end{array}$ & $\begin{array}{l}100 \cdot 4(0 \cdot 6) \\
102 \cdot 7(0 \cdot 1)\end{array}$ & $\begin{array}{l}100 \cdot 6(0 \cdot 5) \\
103 \cdot 1(0 \cdot 2)\end{array}$ & $\begin{array}{l}100.0(0.9) \\
102.9(0.2)\end{array}$ & $\begin{array}{r}<0.001 \\
0.166\end{array}$ \\
\hline
\end{tabular}

${ }^{\star} \mathrm{p}$ value is for analysis of variance. Values in parentheses are standard deviations. $\mathrm{BP}=$ mean blood pressure; $\mathrm{PaO}_{2}=$ arterial $\mathrm{PO}_{2} ; \mathrm{PaCO}_{2}=$ arterial $\mathrm{PCO}_{2}$.

1.3 (SD 1.6) hours in the patients who died, compared to 0.4 (SD 0.8 ) hours in patients with a good recovery or moderate disability, and 0.4 (SD 1.1) hours in patients who had a severe disability or were vegetative.

RELATIONSHIP OF OTHER FACTORS TO NEUROLOGICAL OUTCOME

Many factors have been associated with outcome after severe head injury, including age, severity of injury, type of injury, presence of systemic injuries, severity of intracranial hypertension, and level of CBF. The relationship of the demographic factors to neurological outcome in the 116 patients are summarised in table 1. Age was not significantly associated with outcome, although there was a trend for the patients with a favourable outcome to be younger.

The severity of injury was examined in the emergency room by using the best GCS and pupillary reactivity on day 1 after injury. The GCS after resuscitation in the emergency room was not significantly associated with neurological outcome, but the best GCS on day 1 after injury had a strong relationship to outcome, averaging $8 \cdot 1$ (SD $2 \cdot 3$ ) in patients with a favourable outcome, compared to 6.5 (SD 2.7) in patients with a poor outcome, and $5 \cdot 5($ SD $2 \cdot 2)$ in patients who died. Pupillary size and reactivity in the emergency room and on day 1 were strongly related to outcome. Patients who died of their head injury had a higher incidence of one or both pupils being dilated and unreactive.

Sixteen $(14 \%)$ of the patients had a gunshot wound to the head and $100(86 \%)$ had closed head injuries. The type of closed head injury was classified as described by the Traumatic Coma Data Bank group. ${ }^{19}$ Thirtyeight $(38 \%)$ of the patients with closed head injuries had one of the four categories of diffuse injury (6-I, 19-II, 11-III, and 2-IV). Fifty-four (54\%) had evacuated haematomas of at least $25 \mathrm{ml}$ in volume, and eight (8\%) had unevacuated haematomas. The neurological outcome of patients with diffuse lesions was significantly better than for those with haematomas and gunshot wounds. Twenty-one $(55 \%)$ of the 38 patients with diffuse lesions had a favourable outcome compared to only $16(26 \%)$ of the 62 patients with haematomas and three $(19 \%)$ of the 16 patients with gunshot wounds. The mortality rate was $16 \%$ in patients with diffuse injuries, $43.5 \%$ in those with haematomas, and $19 \%$ in those with gunshot wounds.

The injury severity score (ISS) was used to assess whether multiple systemic injuries were associated with neurological outcome. An ISS

Table 3 Cerebral physiological variables that were examined for an effect on the relationship between desaturations and outcome

\begin{tabular}{|c|c|c|c|c|c|c|c|c|}
\hline & \multicolumn{4}{|c|}{ Number of desaturations } & \multicolumn{4}{|c|}{ Three month Glasgow outcome score } \\
\hline & None & One & Multiple & $p$ value* & $G R / M D$ & $S D / V$ & Dead & p value ${ }^{\star}$ \\
\hline $\begin{array}{l}\text { Number of patients } \\
\text { ICP (mmHg) }\end{array}$ & 70 & 27 & 19 & & 40 & 40 & 36 & \\
\hline $\begin{array}{l}\text { Mean } \\
\text { Highest } \\
\text { CPP (mm }\end{array}$ & $\begin{array}{l}17(6) \\
35(12)\end{array}$ & $\begin{array}{l}22(9) \\
47(22)\end{array}$ & $\begin{array}{l}21(12) \\
43(24)\end{array}$ & $\begin{array}{l}0.008 \\
0.009\end{array}$ & $\begin{array}{l}15(5) \\
33(11)\end{array}$ & $\begin{array}{l}16(5) \\
34(11)\end{array}$ & $\begin{array}{l}25(10) \\
53(23)\end{array}$ & $\begin{array}{l}<0.001 \\
<0.001\end{array}$ \\
\hline $\begin{array}{l}\text { CPP (mmHg) } \\
\text { Mean } \\
\text { Lowest }\end{array}$ & $\begin{array}{l}76(9) \\
48(14)\end{array}$ & $\begin{array}{l}70(17) \\
33(28)\end{array}$ & $\begin{array}{l}64(20) \\
33(30)\end{array}$ & $\begin{array}{l}0.003 \\
0.001\end{array}$ & $\begin{array}{l}78(7) \\
53(10)\end{array}$ & $\begin{array}{l}78(9) \\
49(15)\end{array}$ & $\begin{array}{l}60(17) \\
22(26)\end{array}$ & $\begin{array}{l}<0.001 \\
<0.001\end{array}$ \\
\hline $\begin{array}{l}\mathrm{CBF}(\mathrm{ml} / \mathrm{g} \text { per min }) \\
\text { Mean } \\
\text { Lowest } \\
\text { SivO }(\%)\end{array}$ & $\begin{array}{l}0.523(0.146) \\
0.459(0.156)\end{array}$ & $\begin{array}{l}0.516(0.147) \\
0.415(0.140)\end{array}$ & $\begin{array}{l}0.464(0.178) \\
0.429(0.186)\end{array}$ & $\begin{array}{l}0 \cdot 314 \\
0 \cdot 421\end{array}$ & $\begin{array}{l}0.544(0.163) \\
0.465(0.163)\end{array}$ & $\begin{array}{l}0.530(0 \cdot 148) \\
0.433(0 \cdot 155)\end{array}$ & $\begin{array}{l}0.456(0.130) \\
0.434(0.157)\end{array}$ & $\begin{array}{l}0.024 \\
0.590\end{array}$ \\
\hline $\begin{array}{l}\mathrm{SjvO}_{2}(\%) \\
\text { Mean } \\
\text { Lowest } \\
\text { No of times }<50 \% \\
\text { Time }<50 \%(\mathrm{~h}) \\
\mathrm{CMRO}_{2}(\mu \mathrm{mol} / \mathrm{g} \text { per min })\end{array}$ & $\begin{array}{l}71(6) \\
50 \\
0 \\
0\end{array}$ & $\begin{array}{l}69(7) \\
43(1) \\
1 \cdot 4(0 \cdot 3) \\
1 \cdot 4(0.3)\end{array}$ & $\begin{array}{l}68(5) \\
34(2) \\
>1 \cdot 9(0 \cdot 4)\end{array}$ & $\begin{array}{r}0.059 \\
<0.001 \\
<0.001\end{array}$ & $\begin{array}{l}69(5) \\
51(7) \\
0 \cdot 3(0 \cdot 6) \\
0.4(1 \cdot 1)\end{array}$ & $\begin{array}{l}70(5) \\
50(9) \\
0 \cdot 4(0 \cdot 7) \\
0 \cdot 4(0 \cdot 8)\end{array}$ & $\begin{array}{l}71(7) \\
45(13) \\
1 \cdot 0(0 \cdot 8) \\
1 \cdot 3(1 \cdot 6)\end{array}$ & $\begin{array}{r}0.325 \\
0.027 \\
<0.001 \\
0.002\end{array}$ \\
\hline $\begin{array}{l}\mathrm{Mean}_{2}(\mu \mathrm{mol} / \mathrm{g} \text { per min }) \\
\text { Lowest } \\
\text { CVR }(\mathrm{mmH} H \mathrm{mg} / \mathrm{ml} \text { per } 100 \mathrm{~g} \\
\text { per min) }\end{array}$ & $\begin{array}{l}1.00(0.39) \\
0.62(0.28)\end{array}$ & $\begin{array}{l}1.09(0.53) \\
0.69(0.47)\end{array}$ & $\begin{array}{l}0.94(0.30) \\
0.54(0.29)\end{array}$ & $\begin{array}{l}0.433 \\
0.340\end{array}$ & $\begin{array}{l}1.12(0.41) \\
0.73(0.35)\end{array}$ & $\begin{array}{l}1.03(0.43) \\
0.61(0.32)\end{array}$ & $\begin{array}{l}0.86(0.35) \\
0.52(0.30)\end{array}$ & $\begin{array}{l}0.017 \\
0.017\end{array}$ \\
\hline $\begin{array}{l}\text { per min) } \\
\text { Mean }\end{array}$ & $1.94(0.58)$ & $1.57(0.50)$ & $1.79(0.75)$ & 0.480 & $1.65(0.49)$ & $1.73(0.67)$ & $1.56(0.61)$ & 0.491 \\
\hline
\end{tabular}

${ }^{\star} \mathrm{p}$ value is for analysis of variance. Values in parentheses are standard deviations. $\mathrm{ICP}=$ intracranial pressure; $\mathrm{CPP}=\mathrm{cerebral}$ perfusion pressure; $\mathrm{CBF}=\mathrm{cerebral}$ blood flow; $\mathrm{SjVO}_{2}=$ jugular venous oxygen saturation; $\mathrm{CMRO}_{2}=$ cerebral metabolic rate of oxygen; $\mathrm{CVR}=$ cerebral vascular resistance. 
Table 4 Final logistic regression model for poor neurological outcome (severe disability, vegetative, or dead three months after injury) as dependent variable

\begin{tabular}{|c|c|c|}
\hline Variable/Category & $\begin{array}{l}\text { Odds } \\
\text { ratio }\end{array}$ & p value \\
\hline $\begin{array}{l}\text { Number of desaturations } \\
\text { Multiple } \\
\text { One } \\
\text { None }\end{array}$ & $\begin{array}{r}14 \cdot 46 \\
2 \cdot 09 \\
1 \cdot 00\end{array}$ & $\begin{array}{l}0.0348 \text { (overall variable) } \\
0.012 \\
0 \cdot 289\end{array}$ \\
\hline $\begin{array}{l}\text { Type of injury } \\
\text { Gunshot wound } \\
\text { Closed head injury- } \\
\text { hematoma } \\
\text { Closed head injury- } \\
\text { diffuse }\end{array}$ & $\begin{array}{l}4 \cdot 39 \\
4 \cdot 60 \\
1 \cdot 00\end{array}$ & $\begin{array}{l}0.0652 \text { (overall variable) } \\
0.253 \\
0.021\end{array}$ \\
\hline $\begin{array}{l}\text { Day } 1 \\
\text { Glasgow coma score } \\
3-5 \\
6-8 \\
9-15\end{array}$ & $\begin{array}{r}41 \cdot 79 \\
8 \cdot 61 \\
1 \cdot 00\end{array}$ & $\begin{array}{l}0.0025 \text { (overall variable) } \\
0.000 \\
0.005\end{array}$ \\
\hline $\begin{array}{l}\text { Pupillary reactivity } \\
\text { One or both dilated } \\
\text { and unreactive } \\
\text { Neither unreactive } \\
\text { Highest temperature }\end{array}$ & $\begin{array}{r}21.55 \\
1.00\end{array}$ & 0.052 \\
\hline $\begin{array}{l}\text { (per }{ }^{\circ} \mathrm{F} \text { increase) } \\
\text { Lowest cerebral perfusion } \\
\text { pressure (per mmHg } \\
\text { increase) } \\
\text { Age (per year increase) }\end{array}$ & $\begin{array}{l}0.94 \\
1.06\end{array}$ & $\begin{array}{l}0.004 \\
0.017\end{array}$ \\
\hline
\end{tabular}

of 25 indicates the presence of only a severe head injury. The presence of systemic injuries increases the score, depending on their severity. The ISS was not significantly related to neurological outcome.

The relationships of the physiological variables to outcome are listed in tables 2 and 3 . The mean and the highest recorded ICP values, the mean and the lowest blood pressure values, the mean and the lowest CPP values, the mean $\mathrm{PaCO}_{2}$, and the mean temperature were all significantly related to outcome. The mean CBF was lower in patients who died. The mean and the lowest cerebral metabolic rate of oxygen $\left(\mathrm{CMRO}_{2}\right)$ values were significantly lower in the patients who died.

\section{Logistic regression analysis}

To determine whether the difference in neurological outcome with jugular desaturation reflected the effect of other co-variates, logistic regression analysis was used as described above. The final best fit model is shown in table 4 . When the effect of jugular desaturation was adjusted for all other co-variates which were found to be significant, including age, severity of injury (day 1 GCS and pupillary reactivity), type of injury (CT category), lowest recorded CPP, and highest recorded temperature, the incidence of jugular desaturation was still significant $(p=0.03)$. A single episode of desaturation resulted in a doubling of the probability of a poor outcome, and multiple episodes of desaturation were associated with a 14-fold higher probability of a poor outcome.

\section{Discussion}

Although the critical level for $\mathrm{SjvO}_{2}$, below which the brain is ischaemic, has not been established definitely, a few studies suggest that an $\mathrm{SjvO}_{2}$ value of $<50 \%$ can be related to cerebral ischaemia. Continuous monitoring of oxygen saturation in the lateral sinus, during carotid endarterectomy in 50 patients, revealed that cerebral dysfunction was found in patients with a venous oxygen saturation $\left(\mathrm{SvO}_{2}\right)<50 \%$, and there were no cases of dysfunction when $\mathrm{SvO}_{2}$ remained at least $60 \% .^{20}$ EEG slowing appeared when jugular venous $\mathrm{PjvO}_{2}$ ) fell to $<2.5 \mathrm{kPa}\left(19 \mathrm{mmHg}\right.$ ) (an $\mathrm{SjvO}_{2}$ value of about $40 \%$ ) in 19 healthy volunteers. ${ }^{21}$ Neurological deterioration occurred in head injured patients when the $\mathrm{SjvO}_{2}$ value was $<30 \%$ for more than 10 minutes. ${ }^{22}$

The critical duration of ischaemia necessary to produce injury is not known, but experimental studies suggest that brief episodes of ischaemia can be injurious, particularly if they are repeated. Cerebral oedema and brain tissue injury were more severe in gerbils sacrificed 24 hours after three separate five-minute periods of bilateral carotid occlusion at one-hour intervals than in animals which received a single 15-minute occlusion. ${ }^{23-25}$

There are several limitations to the methodology of the present study which might have underestimated the actual incidence of cerebral ischaemia. $\mathrm{SjvO}_{2}$ values are a measure of global cerebral oxygenation, and significant regional ischaemia can occur in the presence of a normal $\mathrm{SjvO}_{2}$ value. Systemic insults on admission to the hospital have been shown to increase mortality rate approximately twofold. ${ }^{3426}$ Andrews et al ${ }^{27}$ found a significant incidence of secondary insults during within hospital transfers of head injured patients. Insults before admission and during transfer were not monitored in the present study. Very low CBF values, suggesting ischaemia have been described after a severe head injury, but only commonly within the first eight hours. ${ }^{28} 29$ The average start time of $\mathrm{SjvO}_{2}$ monitoring in the present study was 17 hours after admission.

The present study demonstrates that episodes of jugular venous desaturation are common during the first five days after severe head injury, and that these episodes are the result of both systemic and cerebral causes, some of which are treatable. The occurrence of jugular venous desaturation is strongly associated with a poor neurological outcome. Although a cause and effect relationship with outcome cannot be established in the present study, it is reasonable to hypothesise that monitoring $\mathrm{SjvO}_{2}$ might allow early identification and therefore treatment of a number of causes of secondary injury to the brain.

This work was supported by United States Public Health Service Grant PO1-NS27616.

1 Marmarou A, Anderson RL, Ward JD, et al. Impact of ICP instability and hypotension on outcome in patients with instability and hypotension on outcome in patie

2 Miller ID, Becker DP, Ward JD, Sullivan HG, Adams WB, Rosner MJ. Significance of intracranial hypertension in severe head injury. 7 Neurosurg 1977;47:503-16.

Kohi YM, Mendelow AD, Teasdale GM, Allardice GM. Kohi YM, Mendelow AD, Teasdale GM, Allardice GM.
Extracranial insults and outcome in patients with acute Extracranial insults and outcome in patients with acute
head injury-relationship to the Glasgow Coma Scale. head injury-relations

4 Miller JD, Becker DP. Secondary insults to the injured brain. F $R$ Coll Surg Edinb 1982;27:292-8. 
5 Muizelaar JP, Marmarou A, Ward JD, et al. Adverse effects of prolonged hyperventilation in patients with severe head injury: a randomized clinical trial. $\mathfrak{f}$ Neurosurg 1991;75:731-9.

6 Miller JD, Butterworth JF, Gudeman SK, et al. Further experience with the management of severe head injury. experience with the managem
f Neurosurg $1981 ; 54: 289-99$.

7 Andrews PJ, Dearden NM, Miller JD. Jugular bulb cannulation: description of a cannulation technique and validation of a new continuous monitor. $B r \mathcal{F}$ Anaesth 1991; 67:553-8.

$8 \mathrm{Cruz}$ J. Continuous versus serial global cerebral hemometabolic monitoring: applications in acute brain trauma. Acta Neurochir 1988;42(suppl):35-41.

9 Cruz J, Miner ME, Allen SJ, et al. Continuous monitoring of cerebral oxygenation in acute brain injury: assessment of cerebral hemodynamic reserve. Neurosurgery 1991;29: 743-9.

10 Garlick R, Bihari D. The use of intermittent and continuous recordings of jugular venous bulb oxygen saturation in the unconscious patient. Scand 7 Clin Lab Invest 1987; 47(suppl 188):47-52.

11 Hans P, Franssen C, Damas F, Born JD, Lamy M. Continuous measurement of jugular venous bulb oxygen saturation in neurosurgical patients. Acta Anaesthesiol saturation in neuro

12 Sheinberg M, Kanter JM, Robertson CS, Contant CF, Narayan RK, Grossman RG. Continuous monitoring of jugular venous oxygen saturation in head-injured patients. I Neurosurg 1992;76:212-7.

13 Cruz J. Combined continuous monitoring of systemic and cerebral oxygenation in acute brain injury: preliminary observations. Crit Care Med 1993;21:1225-32.

14 Chan K-H, Miller JD, Dearden NM, Andrews PJD, Midgley $S$. The effect of changes in cerebral perfusion pressure upon middle cerebral artery blood flow velocity and jugular bulb venous oxygen saturation after severe brain injury. $¥$ Neurosurg 1992;77:55-61.

15 Chan K-H, Dearden NM, Miller JD, Andrews PJD, Midgley S. Multimodality monitoring as a guide to treatment of intracranial hypertension after severe brain ment of intracranial hypertension

16 Robertson CS, Contant CF, Gokaslan ZL, Narayan RK, Grossman RG. Cerebral blood flow and outcome after head injury. If Neurol Neurosurg Psychiatry 1992;55: 594-603.
17 Changaris DG, McGraw CP, Richardson JP, Garretson HD, Arpin DJ, Shields CB. Correlation of cerebral perfusion pressure and Glasgow Coma Scale to outcome. $\mathcal{F}$ Trauma 1987;27:1007-12.

18 Rosner MJ, Daughton $S$. Cerebral perfusion pressure management in head injury. $\mathcal{F}$ Trauma 1990;30:933-41.

19 Marshall LF, Marshall SB, Klauber MR, et al. A new classification of head injury based on computerized classification of head injury based on

20 Lyons C, Clark LC Jr, McDowell H, McArthur K Cerebral venous oxygen content during carotid thrombintimectomy. Ann Surg 1964;160:561-7.

21 Meyers JS, Gotoh F, Ebihara S, Tomita M. Effects of anoxia on cerebral metabolism and electrolytes in man. Neurology 1965;15:892-901.

22 Cruz J. On-line monitoring of global cerebral hypoxia in acute brain injury: relationship to intracranial hypertension. F Neurosurg 1993;79:228-33.

23 Tomida S, Nowak Jr. TS, Vass K, Lohr JM, Klatzo I. Experimental model for repetitive ischemic attacks in the gerbil: the cumulative effect of repeated ischemic insults. gerbil: the cumulative effect of repeated ischemic

24 Vass K, Tomida S, Hossman KA, Nowak TS Jr, Klatzo I. Microvascular disturbances and edema formation after repetitive ischemia of gerbil brain. Acta Neuropathol repetitive ischem

25 Pluta R, Tomida S, Ikeda J, Nowak TS, Jr, Klatzo I. Cerebral vascular volume after repeated ischemic insults in the gerbil: comparison with changes in cerebral blood flow and brain edema. $\mathcal{F}$ Cerebral Blood Flow Metabol 1989;9:163-70.

26 Eisenberg H, Cayard C, Papinicolaou A, et al. The effects of three potentially preventable complications on outcome after severe head injury. In Ishii S, Nagai $\mathrm{H}$, Brock $\mathrm{M}$, eds. Intracranial pressure V. Berlin: Springer-Velag 1983: 549-53.

27 Andrews PJ, Piper IR, Dearden NM, Miller JD. Secondary insults during intrahospital transport of head-injured patients. Lancet 1990;335:327-30.

28 Yoshino $E$, Yamaki T, Higuchi T, Horikawa Y, Hirakawa $K$. Acute brain edema in fatal head injury: analysis by K. Acute brain edema in fatal head injury: analysis

29 Bouma GJ, Muizelaar JP, Choi SC, Newlon PG, Young HF. Cerebral circulation and metabolism after severe traumatic brain injury: the elusive role of ischaemia. f Neurosurg 1991;75:685-93. 